\title{
Prognostic factors for malignant pleural mesothelioma
}

\author{
Fraser J. H. Brims • Nick A. Maskell
}

Published online: 26 February 2013

(C) Springer Science+Business Media New York 2013

\begin{abstract}
The prognosis for patients with malignant pleural mesothelioma (MPM) is generally regarded as poor, although rare cases of long-term survivors are recognised. Previous prognostic scoring systems have been based on clinical trial populations and are not widely utilised. Population studies consistently confirm non-epithelioid histology, advanced age, and male gender as independent risk factors for poor outcome of MPM. Genetic and immunohistochemical studies continue to provide advances in tumour biology, but no clear validated prognostic factors have been identified to date. Nuclear mitotic and atypia grading systems may provide useful prognostic knowledge; further evaluation is needed. Such biomarkers as soluble mesothelin-related protein and osteopontin provide some prognostic information, though with limitations. The baseline serum neutrophil-to-lymphocyte ratio could also provide prognostic information. Modern metabolic imaging techniques, for example PET/CT, can indicate prognosis by use of baseline total glycolytic volumes (TGV). TGV may also be useful in identifying early responders to systemic chemotherapy treatment. Research to identify clinically useful prognostic factors in MPM remains a priority.
\end{abstract}

Keywords Mesothelioma P Prognosis · Prognostic markers · Prognostic factors

\footnotetext{
F. J. H. Brims ( $\square)$

Respiratory Department, Sir Charles Gairdner Hospital, Hospital Avenue, Nedlands,

Perth, WA 6009, Australia

e-mail: fraser.Brims@health.wa.gov.au

N. A. Maskell

School of Clinical Sciences, University of Bristol, Bristol, UK

e-mail: nick.maskell@bristol.ac.uk
}

\section{Introduction}

Malignant pleural mesothelioma (MPM) is a heterogeneous disease with reported median survival of 8-12 months. Because the vast majority of mesothelioma cases are caused by exposure to asbestos, the disease can affect a wide age range, and survival and prognosis vary substantially for different populations. There is no cure for MPM; current recognised chemotherapy regimes may improve survival by a few months [1]. Therefore the prognosis for MPM is generally regarded as poor, although 3-5\% of patients may survive more than five years.

Prognostic factors for any disease are important and useful, because they can enable stratification into risk groups which can, in turn, be used to facilitate treatment decisions, for example identifying those most likely to benefit from aggressive therapy and predicting response to therapy, or identifying those for whom early palliation may be more appropriate. In recent years there has been much interest in "personalised medicine" as a result of advancing genetic, molecular, and immunohistochemistry techniques that assist identification and understanding of tumour phenotypes, both in cohorts and on an individual level. This individual approach is rapidly becoming part of standard best practice for lung cancer [2], but for MPM similar advances in understanding, and in relating understanding to prognosis, have been lacking.

Several scoring systems have been developed and validated [3-6] but all of these are based on specific, selected clinical trial populations, which limits how well they can be generalised to the larger population of patients with mesothelioma. Consequently, these scoring systems are not widely used in clinical practice.

This review article will summarise published data on different aspects of prognosis for MPM, including results from population-based studies, clinically relevant laboratory 
characteristics and biomarkers, imaging modalities, and genetic and molecular prognostic factors.

\section{Population-based studies}

Although mesothelioma is still regarded as a comparatively rare tumour, several relatively large population-based studies and some smaller studies enable analysis of prognostic variables by use of Cox regression. These national and regional reports are useful because they tend to examine all cases of MPM, and not the more selected populations included in many other studies. A summary of findings from the six most relevant studies is presented in Table 1.

With regard to prognostic variables for poor outcome (shorter survival), frequently-recognised independent risk factors are greater age [7-12], male gender [8, 10, 11], and non-epitheliod or sarcomatoid histology [7, 9-12]. The anatomical site of mesothelioma may be important: a recent study from the Netherlands of 1,353 patients with mesothelioma identified non-pleural disease as a significant prognostic factor (hazard ratio (HR) 1.67, $95 \%$ confidence interval (CI) 1.26-2.22) [7]; and a large study from the USA, including 8,128 patients over 33 years, found localised disease to be protective (HR 0.81, $95 \%$ CI $0.75-0.86$ ) [8]. A smaller regional study from Japan also identified poor performance status (PS of 4 HR 3.22, $95 \%$ CI 1.19-8.74) and high c-reactive protein (CRP) levels (HR 1.8, $95 \%$ CI 1.06-3.06) as significant independent prognostic variables for poor outcome, with high white cell count (HR 1.49, $95 \%$ CI 0.99-2.26) approaching significance [9].

In summary, when a population-based approach is used to establish prognostic data, increased age, non-epithelioid histology, and male gender are the most consistently reported factors associated with poor outcome, with anatomical site (pleural/non-pleural) likely to be important. This finding may complement a recent report describing remarkably large numbers of extrapleural metastases from MPM found at autopsy, although this report was not designed to demonstrate an affect on survival [13]. Although population-based studies have distinct advantages, there is also a need to examine the biology of MPM to further elucidate prognostic factors for survival with MPM.

\section{Histology}

One of the strongest predictors of survival in mesothelioma is histological subtype: many groups, all reaching similar conclusions, have reported this [7, 9]. Epithelioid mesothelioma has slower progression than the sarcomatoid variant. In a large Italian study that included 429 patients, those with sarcomatoid subtype had a hazard ratio of $2.96(95 \% \mathrm{CI}$ $1.28-6.81 ; p=0.02$ ) [12]. In another study involving 4,555

Table 1 Recent population-based studies of malignant mesothelioma examining survival

\begin{tabular}{|c|c|c|c|c|c|}
\hline Location & Years & $N$ & Description & $\begin{array}{l}\text { Prognostic variables identified-worse survival } \\
\text { Hazard ratio }(95 \% \mathrm{CI})\end{array}$ & Ref. \\
\hline Netherlands & $2005-2008$ & 1353 & $\begin{array}{l}\text { Median age } 69 \text { years; } 1 \text {-year } \\
\text { survival } 47 \% ; 91.1 \% \text { male }\end{array}$ & $\begin{array}{l}\text { Increasing age, } 1.04(1.03-1.06) \\
\text { Sarcomatoid histology, } 2.45(2.06-2.90) \\
\text { Non-pleural MPM, } 1.67(1.26-2.22)\end{array}$ & van der Bij, 2012 [7] \\
\hline USA & 1973-2006 & 8128 & $\begin{array}{l}\text { Median age } 72 \text { years; } 1 \text {-year } \\
\text { survival } 33 \% ; 81 \% \text { male }\end{array}$ & $\begin{array}{l}\text { Increasing age, } 1.02(1.019-1.023) \\
\text { Male gender, } 1.23(1.16-1.31) \\
\text { Local disease, } 0.80(0.75-0.86) \\
\text { Treatment: surgery, } 0.66(0.63-0.70)\end{array}$ & Milano, 2010 [8] \\
\hline Japan & 1996-2006 & 347 & $\begin{array}{l}\text { Median age } 67 \text { years; median } \\
\text { survival } 308 \text { days; } 87 \% \text { male }\end{array}$ & $\begin{array}{l}\text { Age }>70 \text { years, } 2.17(1.36-3.46) \\
\text { Non-epithelioid histology, } 1.58(1.15-2.18) \\
\text { ECOG performance score }=4,3.22(1.19-8.74) \\
\text { Raised CRP, } 1.8(1.06-3.06)\end{array}$ & Nojiri, 2011 [9] \\
\hline Italy & 1990-2001 & 4100 & $\begin{array}{l}62 \% \text { aged between } 55-74 \text { years; } \\
\text { median survival } 9.8 \text { months; } \\
73 \% \text { male }\end{array}$ & $\begin{array}{l}\text { Age }>75 \text { years, } 1.9(1.7-2.1) \\
\text { Non-epithelioid histology, } 1.8(1.6-2.0) \\
\text { Male gender, } 1.1(1.0-1.2)\end{array}$ & Montanaro, 2009 [10] \\
\hline Germany & $1987-2000$ & 498 & Mean age 63.1 years, $87 \%$ male & $\begin{array}{l}\text { Age }>60 \text { years, } 1.29 \text { (No CIs presented) } \\
\text { Sarcomatoid histology, } 1.89 \text { (No CIs presented) } \\
\text { Male gender, } 1.72 \text { (No CIs presented) }\end{array}$ & Neuman, 2004 [11] \\
\hline Italy & 1997-2001 & 429 & $\begin{array}{l}\text { Median survival } 275 \text { days; } \\
71.6 \% \text { male }\end{array}$ & $\begin{array}{l}\text { Age }>75,1.82(1.16-2.86) \\
\text { MPM "suspected", } 1.85(1.16-2.94) \\
\text { Sarcomatoid histology, } 2.96(1.28-6.81)\end{array}$ & Marinaccio, 2003 [12] \\
\hline
\end{tabular}

$C I$ confidence interval; MPM malignant pleural mesothelioma; ECOG European Cancer Oncology Group; CRP c-reactive protein 
German patients on a national register, favourable prognostic factors for long-term survival included epithelioid tumour subtype [11].

In a report from the USA on 232 archived mesothelioma samples (all epithelioid histology), the histological analysis and grading of nuclear atypia and mitotic count were found, by multivariate logistic regression (MLR; nuclear atypia severe vs. mild: HR 1.89, $95 \%$ CI 1.15-3.10; mitotic count high vs. low: HR 2.79, $95 \%$ CI 1.69-4.59) to be independent prognostic factors [14•]. A grading system based on these results was used to stratify clinicopathological factors by nuclear grade; it revealed statistical association of higher grade nuclear atypia and mitotic count with lymphatic and vascular invasion, and tumour, nodal, and overall stage. These results must be validated externally, and must also be tested on non-epithelioid histology specimens before wider interpretation. A smaller, earlier report on 40 surgical MPM cases, using an index of mitotic activity (in association with assessment of tumour necrosis and vascular endothelial growth factor), failed to demonstrate any independent significance [15].

Angiogenesis is essential for tumour growth beyond a few millimetres. Edwards et al. reported the use of microvessel density (MVD) to score angiogenesis for archived, surgically resected MPM samples. They discovered, by MLR, that increased MVD levels are an independent prognostic factor for poor MPM survival in this surgical group [16]. In a similar report from the same group on a larger cohort of 171 radical, debulking, and palliative surgery specimens, a high MVD score (i.e. increased angiogenesis) was statistically associated with tumour necrosis scores, with the degree of tumour necrosis also contributing independently as a risk factor for shorter survival [17]. A similar report on 40 surgical MPM specimens demonstrated univariate statistical significance of tumour necrosis for shorter survival, but this was no longer significant after multivariate analysis [15].

\section{Immunohistochemical markers}

Over the last decade there have been significant advances regarding immunohistochemical markers for MPM and many other solid tumours. A summary of eleven relevant reports that examine survival as an independent variable is presented in Table 2 . These reports are mostly on relatively small, and frequently highly selected (e.g. surgical), populations, limiting how well they generalise to the wider population. Also, many of these studies require external validation $[15,18-26]$ - with the exception of the recent work by Kao et al., who present data validated for both surgical and conservatively managed cohorts with a range of histology subtypes [27•].
Aside from the clear utility of immunohistochemical markers in diagnosis of MPM, at present there is no immunostain, or combination of immunostains, providing reliable prognostic information for clinicians.

\section{Differential gene expression}

The relationship between gene expression and prognosis has only been reported in a small number of studies, which again were limited by sample size and population selection. One of the most common genetic alterations in MPM is homozygous deletion of the 9p21 locus, which contains, among others, the CDKN2A gene that encodes methylthioadenosine phosphorylase, an enzyme involved in the salvage pathway of AMP synthesis [28]. Two papers have reported the effects of the homozygous deletion of P16/CDKN2A on MPM prognosis. Lopez-Rios et al. describe a large series examining 99 MPM samples (75 male) and report that a homozygous deletion of P16/CDKN2A is independently associated with worse overall survival [29]. A later report from Dacic et al. on epithelioid MPM biopsy or pleurectomy samples from a smaller population $(n=48)$ seems to confirm this finding [30]. However, this report was examining a highly selected population of long survivors (median 36 months) with epithelioid histology, which limits how well the study generalises, especially as the use of aggressive surgery in management of MPM is increasingly contentious. Nevertheless, this finding may provide insight into some genetic aspects of long survival.

The serine protease HtrAl is a potential tumour suppressor gene, and a report from Baldi et al. on 70 MPM samples of mixed histology demonstrated, by MLR, that upregulated HtrA1 was independently associated with improved overall survival [31]. These findings from open biopsy and pleurectomy samples should be replicated.

Busacca et al. report a small study of in-vitro and MPM samples with mixed histological subtypes which demonstrated different expression of MicroRNAs (miRNAs) among histological subtypes, and reduced expression of specific miRNA regions and different survival among sarcomatoid subtypes [32]. MicroRNAs may act as tumour suppressors or oncogenes, and this report on only 24 specimens and eight sarcomatoid samples requires further appraisal.

A report by Fischer and co-workers described epigenetic alteration by methylation of specific promoter regions of the $R A S S F 1 A, R A R \beta$, and DAPK genes that correlated with overall survival in a small sample of 43 MPM patients [33]. Hypermethylation may increase tumorigenic properties, and some demethylating agents have been found to have antitumor activity in MPM. These findings, and the emerging use of epigenetics in the diagnosis of mesothelioma, and assessment of prognosis, require further evaluation. 


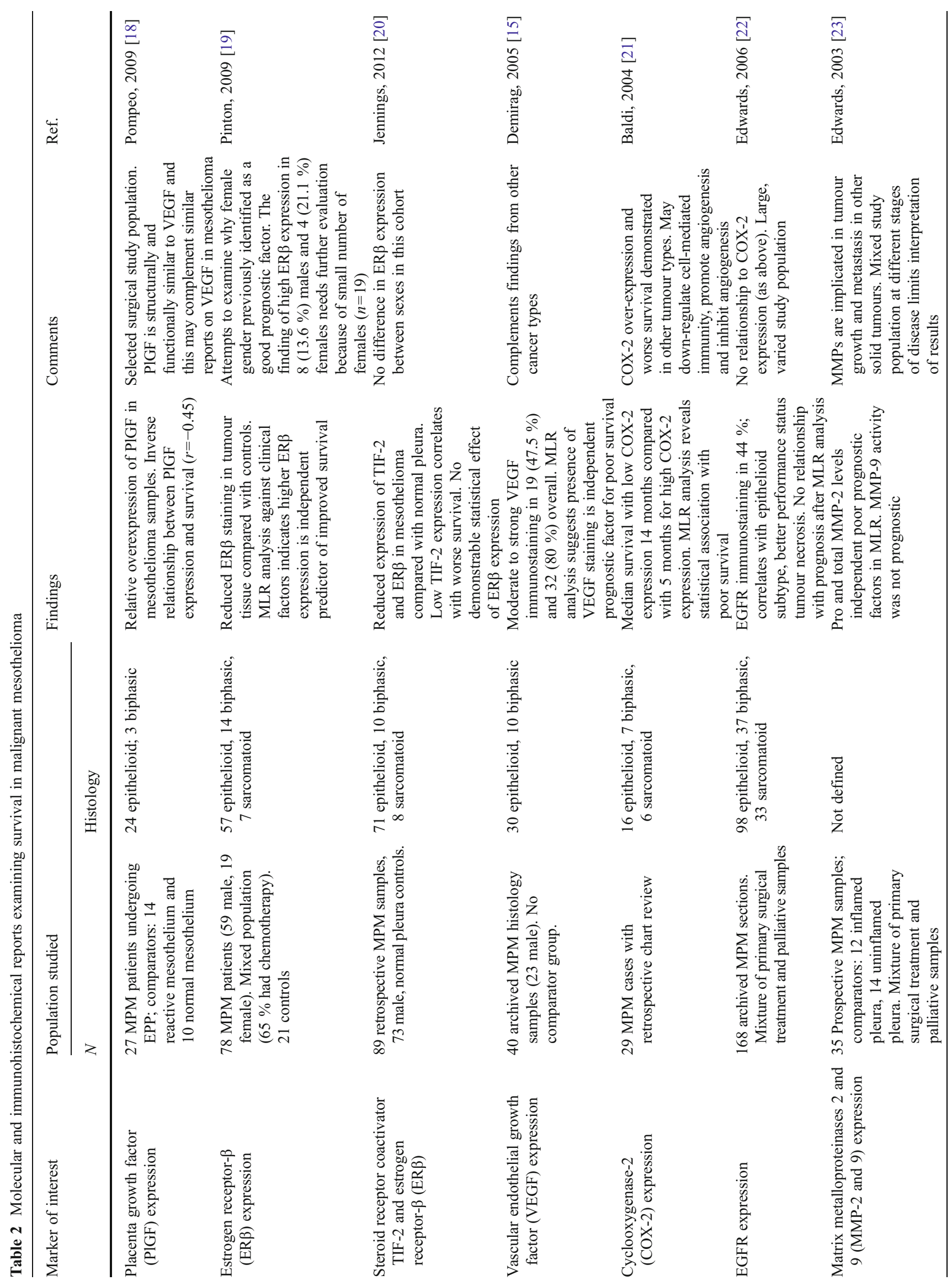




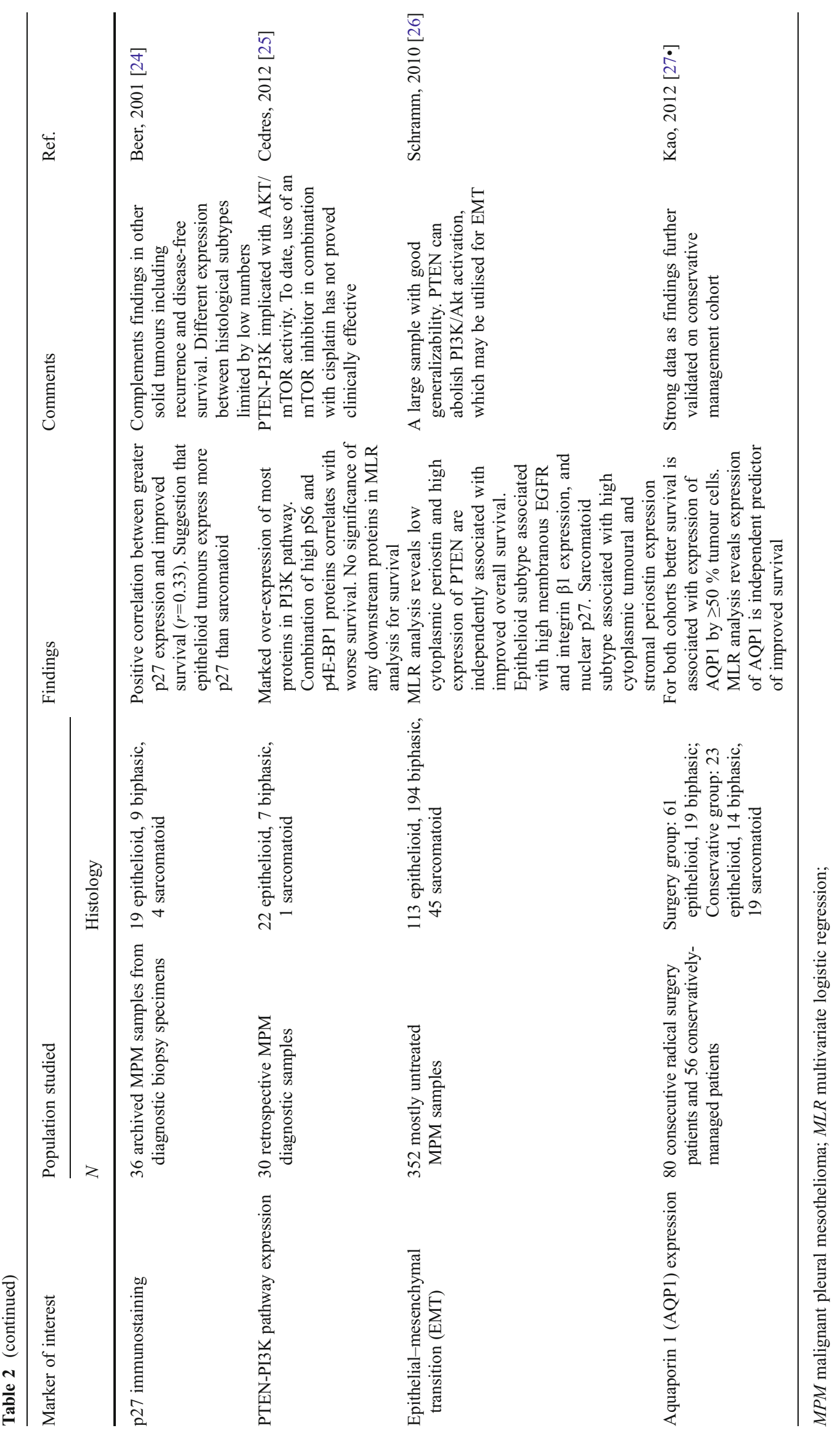


The reports summarised above provide interesting information, with the potential to advance our understanding of the genetics of tumour biology and prognosis in MPM, but none yet delivers markers or quantitative data that have direct prognostic relevance for clinicians.

\section{Biomarkers}

The use of a specific biomarker, or combination of readilyavailable quantitative laboratory variables, to aid diagnosis of MPM and to determine prognosis is highly desirable, because of the ease of sampling (e.g. blood or body cavity fluid) and the potential to assess disease expression and response to treatment. We discuss several relevant biomarkers below.

\section{Vascular Endothelial Growth Factor (VEGF)}

VEGF is a family of proteins which have been shown to be important in angiogenesis and vascular permeability. Tissue VEGF has been shown to correlate with microvessel density, and mesothelioma patients expressing high levels of this cytokine within the tumour have been shown to have a poor prognosis [15]. VEGF is an autocrine growth factor for MPM, and the predictive value of circulating VEGF was the subject of early study in mesothelioma.

Serum VEGF levels were measured in 51 patients with MPM and in 42 individuals with benign asbestos-related diseases. Patients with MPM had higher levels of VEGF than those with benign disease. Within the MPM study population, high levels of serum VEGF $\left(>460 \mathrm{pg} \mathrm{mL}^{-1}\right.$ ) were associated with poor survival [34]. In another study, pleural fluid VEGF was measured in 46 MPM patients and in 45 individuals with other causes of pleural effusion. Patients with MPM had higher levels than other pleural effusion patients, and levels $>2000 \mathrm{pg} \mathrm{mL}^{-1}$ were associated with poorer survival in the MPM subgroup [35].

\section{Neutrophil-to-lymphocyte ratio (NLR)}

Inflammation strongly affects the development and progression of cancers, and release of proinflammatory cytokines in patients with MPM can produce systemic inflammatory symptoms, for example fever, sweating, and weight loss. The neutrophil-to-lymphocyte ratio (NLR) is believed to be a marker of systemic inflammation and can be simply calculated from a full blood count that includes the differential white cell count. A high ratio suggests greater systemic inflammation.

Kao et al. retrospectively studied 173 MPM patients undergoing systemic therapy. Forty-two percent had elevated NLR at baseline. Epithelioid histology (HR 2.0, $95 \%$ CI 1.3-2.9) and NLR of five or below (HR 2.7, $95 \%$ CI 1.8-3.9) were independently predictive of survival [36]. In another study by the same group, 85 patients with MPM undergoing extra-pleural pneumonectomy (EPP) had baseline variable performed; NLR $\geq 3$ was associated with poor prognosis [37•].

\section{Mesothelin and osteopontin}

Mesothelin is a cell-surface glycoprotein expressed on normal mesothelial cells which is involved in cell adhesion. In MPM mesothelin is often over-expressed and may be released from the cell surface in the form of soluble mesothelin (also known as soluble mesothelin-related peptides (SMRPs)). SMRPs can be detected in the blood and pleural fluid by use of commercially available ELISA.

Creaney et al. prospectively studied 97 patients with MPM, measuring baseline and serial serum mesothelin levels. Baseline mesothelin levels $>5 \mathrm{nmol} \mathrm{L}^{-1}$ were a significant negative prognostic indicator (HR 2.25, $95 \%$ CI 1.2-4.21) and correlated with tumour stage and volume. For 55 patients receiving chemotherapy, changes in mesothelin correlated with radiological response. Median survival for patients with a decrease in mesothelin after chemotherapy was substantially longer than for those with increased mesothelin (19 months vs. 5 months $p<0.001)$ [38•].

Preliminary data indicate that changes in serum mesothelin level over time could be used to monitor disease progression and response to treatment in mesothelioma. A rising mesothelin level of $>10 \%$ despite treatment was associated with a worse outcome than that for patients for whom the serum mesothelin level remained stable [39•].

One of the main limitations of mesothelin is the number of MPM patients with serum mesothelin levels below the limits of detection. This is most common among patients with sarcomatoid mesothelioma.

Osteopontin is another glycoprotein; it modulates cellmatrix interactions and is over-expressed by mesothelioma. In an observational study from Belgium, high osteopontin levels were found to be an independent negative predictor of survival with mesothelioma, although less closely associated with treatment response than serum mesothelin levels were [40]. Grigoriu et al. also found that serum mesothelin $>3.5 \mathrm{nmol} \mathrm{L}^{-1}$ and osteopontin $>350 \mathrm{ng} \mathrm{mL}^{-1}$ were both associated with poorer prognosis for patients with mesothelioma [41].

\section{Imaging modalities: CT and PET}

Accurate evaluation of response to treatment in MPM can be difficult to measure on $\mathrm{CT}$ because mesothelioma usually 
presents as a multifocal pleural abnormality, rather than a single tumour mass. It is usually crescent-shaped, rather than spherical, and it is, therefore, difficult to measure disease progression using the standard RESIST criteria. Attempts to address these issues by use of modified RESIST criteria have been made by Nowak and colleagues [42]; however, the pleural cavity is often fibrotic (particularly in sarcomatoid cases), and tumour death within fibrotic pleura is difficult to differentiate. This has led researchers to look at integrated 2-deoxy-2-(F-18)fluoro-D-glucose-positron emission tomography/computed tomography $\left({ }^{18} \mathrm{~F}-\mathrm{FDG}\right.$ PET/CT), both as a baseline prognostic tool and as a potential metabolic marker of response to chemotherapy.

Nowak et al. studied 89 patients with proved mesothelioma, 28 of whom had had a talc pleurodesis before enrolment. All had ${ }^{18} \mathrm{~F}-\mathrm{FDG}$ PET/CT at baseline, and PET variables studied included total glycolytic volume (TGV), a composite of tumour volume and glycolytic activity. By use of univariate analysis, significant baseline prognostic factors were: total glycolytic volume, sarcomatoid histology, weight loss, CT stage, and EORTC prognostic score. In multivariate analysis, only histology and TGV remained predictive of survival. In non-sarcomatoid disease TGV was more predictive of survival than CT staging. Pleurodesis induces an intense inflammatory response in the pleura, which may result in false positive uptake on FDG-PET imaging. However, the TGV value obtained remained a strong predictor of survival in both the pleurodesis and non-pleurodesis group [43].

In another study of 46 patients with biopsy-proven mesothelioma, all had ${ }^{18} \mathrm{~F}-\mathrm{FDG}$ PET/CT at baseline and the SUV $_{\max }$ was calculated. ${ }^{18} \mathrm{~F}$-FDG PET/CT was better than $\mathrm{CT}$ at detecting metastatic disease (9/46, $20 \%$ ) [44]. Most of these (8/9) had not previously been detected by CT imaging. Evaluation of progression-free survival by Kaplan-Meier analysis did not correlate with $\mathrm{SUV}_{\max }$. In this study, nonepithelioid histology and presence of metastatic disease were the only markers of poor prognosis.

In a further small study, by the same group, of 13 patients due to undergo extrapleural pneumonectomy (EPP) or palliative chemotherapy, ${ }^{18} \mathrm{~F}$-FDG PET/CT was used to measure $\mathrm{SUV}_{\text {max }}, \mathrm{SUV}_{\text {avg }}$, metabolic tumour volume (MTV), and total lesion glycolysis (TLG). TLG was obtained by multiplying MTV by $\operatorname{SUV}_{\text {avg. }}$. High TLG $(>1,250)$ or MTV $(>250)$ at baseline were associated with poor prognosis and a short time to disease progression (TTP). No such association was observed for $\mathrm{SUV}_{\max }$ [45].

For patients with mesothelioma the volume-based variable TGV can be easily measured by semiquantitative ${ }^{18}$ F-FDG PET/CT. It can be used to identify early responders to chemotherapy; Francis et al. showed that a $30 \%$ fall in TGV after one cycle of chemotherapy was strongly predictive of survival [42]. This must be confirmed for other cohorts, but suggests that ${ }^{18} \mathrm{~F}$-FDG PET is likely to be an important research tool when evaluating response to novel treatment.

In summary, ${ }^{18} \mathrm{~F}$-FDG PET/CT seems to provide useful data for patients with mesothelioma. It is better at detecting metastatic disease and, although $\mathrm{SUV}_{\max }$ does not correlate with survival, TGV does. In addition, falling TGV levels on repeat imaging after chemotherapy are indicative of "metabolic responders", who seem to have a better prognosis than those with rising TGV levels.

\section{Conclusions}

Population-based studies consistently indicate that increased age, male gender, and non-epithelioid histology are poor prognostic factors. There is interest in the utility of mitotic activity and nuclear atypia for assessment of tumours, although this work needs further validation. There are increasing immunohistochemical and genetic profiling reports of MPM that, at present, do not provide clear, validated prognostic data, although these modalities are likely to provide the most significant advances in our future understanding of tumour biology and prognosis. Biomarkers from serum or pleural fluid do provide some prognostic information, although with limitations, because of different expression by different histological subtypes. Their use in monitoring response to treatment is the subject of a large multi-centre UK-based trial (the SWAMP trial; UKCRN ID 8458), which is due to report its findings shortly. Modern metabolic imaging modalities, for example PET/CT are able to provide prognostic information, particularly regarding response to treatment.

At present much of the tissue biology literature is based on predominantly surgical specimens; this is a selected population and not necessarily representative of the wider population. However, anecdote suggests that long survivors will frequently have similar characteristics to surgical populations, so studies of, and reports on, the latter are still valid. It is possible that better understanding of the phenotype of long survivors may, in turn, lead to better understanding of disease prognosis in mesothelioma in general and this should continue to be a research priority.

Overall, the prognosis for mesothelioma is poor. There is, however, wide variation in survival, response to treatment, and disease progression among individuals, which may in part result from the known biological heterogeneity of this cancer. As immunohistochemical and genetic advances continue it may become more apparent why some characteristics of the disease or patient (for example histology or gender) result in a different prognosis. There remains a need for identification of validated, clinically relevant prognostic factors that can be generalised to the wider population with mesothelioma. 
Conflict of Interest Fraser J.H. Brims declares that he has no conflict of interest.

Nick A. Maskell declares that he has no conflict of interest.

\section{References}

Papers of particular interest, published recently, have been highlighted as:

\section{- Of importance}

1. Vogelzang NJ, Rusthoven JJ, Symanowski J, et al. Phase III study of pemetrexed in combination with cisplatin versus cisplatin alone in patients with malignant pleural mesothelioma. J Clin Oncol. 2003;21(14):2636-44. PubMed PMID: 12860938. Epub 2003/07/16. eng.

2. Spira A, Nana-Sinkam SP. Using MicroRNAs to inform clinical decision making in lung cancer: ready for prime time? Am J Respir Crit Care Med. 2012;186(11):1077-9. PubMed PMID: 23204375.

3. Curran D, Sahmoud T, Therasse P, et al. Prognostic factors in patients with pleural mesothelioma: the European Organization for Research and Treatment of Cancer experience. J Clin Oncol. 1998;16(1):145-52. PubMed PMID: 9440736.

4. Herndon JE, Green MR, Chahinian AP, et al. Factors predictive of survival among 337 patients with mesothelioma treated between 1984 and 1994 by the Cancer and Leukemia Group B. Chest. 1998;113(3):723-31. PubMed PMID: 9515850.

5. Edwards JG, Abrams KR, Leverment JN, et al. Prognostic factors for malignant mesothelioma in 142 patients: validation of CALGB and EORTC prognostic scoring systems. Thorax. 2000;55(9):7315. PubMed PMID: 10950889.

6. Steele JP. Prognostic factors for mesothelioma. Hematol/Oncol Clin N Am. 2005;19(6):1041-52. vi. PubMed PMID: 16325122.

7. van der Bij S, Koffijberg H, Burgers JA, et al. Prognosis and prognostic factors of patients with mesothelioma: a populationbased study. Br J Cancer. 2012;107(1):161-4. PubMed PMID: 22644294. Pubmed Central PMCID: 3389430.

8. Milano MT, Zhang H. Malignant pleural mesothelioma: a populationbased study of survival. J Thorac Oncol. 2010;5(11):1841-8. PubMed PMID: 20975379.

9. Nojiri S, Gemba K, Aoe K, et al. Survival and prognostic factors in malignant pleural mesothelioma: a retrospective study of 314 patients in the west part of Japan. Jpn J Clin Oncol. 2011;41(1):32-9. PubMed PMID: 20798232.

10. Montanaro F, Rosato R, Gangemi M, et al. Survival of pleural malignant mesothelioma in Italy: a population-based study. Int J Cancer. 2009;124(1):201-7. PubMed PMID: 18792097.

11. Neumann V, Rutten A, Scharmach M, et al. Factors influencing long-term survival in mesothelioma patients-results of the German mesothelioma register. Int Arch Occup Environ Heal. 2004;77(3):191-9. PubMed PMID: 14991330.

12. Marinaccio A, Nesti M, Regional Operational C. Analysis of survival of mesothelioma cases in the Italian register (ReNaM). Eur J Cancer. 2003;39(9):1290-5. PubMed PMID: 12763219.

13. Finn RS, Brims FJ, Gandhi A, et al. Post mortem findings of malignant pleural mesothelioma: a Two-Centre Study of 318 patients. Chest. 2012 May 10. PubMed PMID: 22576637.

14. - Kadota K, Suzuki K, Colovos C, et al. A nuclear grading system is a strong predictor of survival in epitheloid diffuse malignant pleural mesothelioma. Mod Pathol. 2012;25(2):260-71. PubMed PMID: 21983936. Epub 2011/10/11. eng. A large database which presents what appear to be novel prognositically important factors that, in turn, correlate with recognised clinicopathological findings in mesothelioma such as metastatic spread.

15. Demirag F, Unsal E, Yilmaz A, Caglar A. Prognostic significance of vascular endothelial growth factor, tumor necrosis, and mitotic activity index in malignant pleural mesothelioma. Chest. 2005;128(5):3382-7. PubMed PMID: 16304288.

16. Edwards JG, Cox G, Andi A, et al. Angiogenesis is an independent prognostic factor in malignant mesothelioma. Br J Cancer. 2001;85(6):863-8. PubMed PMID: 11556838. Pubmed Central PMCID: 2375086.

17. Edwards JG, Swinson DE, Jones JL, et al. Tumor necrosis correlates with angiogenesis and is a predictor of poor prognosis in malignant mesothelioma. Chest. 2003;124(5):1916-23. PubMed PMID: 14605068.

18. Pompeo E, Albonici L, Doldo E, et al. Placenta growth factor expression has prognostic value in malignant pleural mesothelioma. Ann Thorac Surg. 2009;88(2):426-31. PubMed PMID: 19632388.

19. Pinton G, Brunelli E, Murer B, et al. Estrogen receptor-beta affects the prognosis of human malignant mesothelioma. Cancer Res. 2009;69(11):4598-604. PubMed PMID: 19487281.

20. Jennings CJ, O'Grady A, Cummins R, et al. Sustained expression of steroid receptor coactivator SRC-2/TIF-2 is associated with better prognosis in malignant pleural mesothelioma. J Thorac Oncol. 2012;7(1):243-8. PubMed PMID: 22011668.

21. Baldi A, Santini D, Vasaturo F, et al. Prognostic significance of cyclooxygenase-2 (COX-2) and expression of cell cycle inhibitors p21 and p27 in human pleural malignant mesothelioma. Thorax. 2004;59(5):428-33. PubMed PMID: 15115874. Pubmed Central PMCID: 1746992.

22. Edwards JG, Swinson DE, Jones JL, et al. EGFR expression: associations with outcome and clinicopathological variables in malignant pleural mesothelioma. Lung Cancer. 2006;54(3):399 407. PubMed PMID: 17049671.

23. Edwards JG, McLaren J, Jones JL, et al. Matrix metalloproteinases 2 and 9 (gelatinases A and B) expression in malignant mesothelioma and benign pleura. Br J Cancer. 2003;88(10):1553-9. PubMed PMID: 12771921. Pubmed Central PMCID: 2377107.

24. Beer TW, Shepherd P, Pullinger NC. p27 immunostaining is related to prognosis in malignant mesothelioma. Histopathology. 2001;38(6):535-41. PubMed PMID: 11422497.

25. Cedres S, Montero MA, Martinez P, et al. Exploratory analysis of activation of PTEN-PI3K pathway and downstream proteins in malignant pleural mesothelioma (MPM). Lung Cancer. 2012;77(1):192-8. PubMed PMID: 22459204.

26. Schramm A, Opitz I, Thies S, et al. Prognostic significance of epithelial-mesenchymal transition in malignant pleural mesothelioma. Eur J Cardiothorac Surg. 2010;37(3):566-72. PubMed PMID: 19781955.

27. - Kao SC, Armstrong N, Condon B, et al. Aquaporin 1 is an independent prognostic factor in pleural malignant mesothelioma. Cancer. 2012;118(11):2952-61. PubMed PMID: 22020536. This paper reports some of the best validated findings from the molecular studies discussed and identifies an important cellular molecule involved in cell motility and proliferation that seems to be prognostically important.

28. Illei PB, Rusch VW, Zakowski MF, Ladanyi M. Homozygous deletion of CDKN2A and codeletion of the methylthioadenosine phosphorylase gene in the majority of pleural mesotheliomas. Clin Cancer Res. 2003;9(6):2108-13. PubMed PMID: 12796375.

29. Lopez-Rios F, Chuai S, Flores R, et al. Global gene expression profiling of pleural mesotheliomas: overexpression of aurora kinases and $\mathrm{P} 16 / \mathrm{CDKN} 2 \mathrm{~A}$ deletion as prognostic factors and critical evaluation of microarray-based prognostic prediction. Cancer Res. 2006;66(6):2970-9. PubMed PMID: 16540645.

30. Dacic S, Kothmaier H, Land S, et al. Prognostic significance of p16/cdkn2a loss in pleural malignant mesotheliomas. 
Virchows Archiv: Int J Pathol. 2008;453(6):627-35. PubMed PMID: 18958493.

31. Baldi A, Mottolese M, Vincenzi B, et al. The serine protease HtrA1 is a novel prognostic factor for human mesothelioma. Pharmacogenomics. 2008;9(8):1069-77. PubMed PMID: 18681782.

32. Busacca S, Germano S, De Cecco L, et al. MicroRNA signature of malignant mesothelioma with potential diagnostic and prognostic implications. Am J Respir Cell Mol Biol. 2010;42(3):312-9. PubMed PMID: 19502386.

33. Fischer JR, Ohnmacht U, Rieger N, et al. Promoter methylation of RASSF1A, RARbeta and DAPK predict poor prognosis of patients with malignant mesothelioma. Lung Cancer. 2006;54(1):109-16. PubMed PMID: 16893590.

34. Yasumitsu A, Tabata C, Tabata R, et al. Clinical significance of serum vascular endothelial growth factor in malignant pleural mesothelioma. J Thorac Oncol. 2010;5(4):479-83. PubMed PMID: 20357617.

35. Hirayama N, Tabata C, Tabata R, et al. Pleural effusion VEGF levels as a prognostic factor of malignant pleural mesothelioma. Respir Med. 2011;105(1):137-42. PMID: 21041073.

36. Kao SC, Pavlakis N, Harvie R, et al. High blood neutrophil-tolymphocyte ratio is an indicator of poor prognosis in malignant mesothelioma patients undergoing systemic therapy. Clin Cancer Res. 2010;16(23):5805-13. PubMed PMID: 20956618.

37. Kao SC, Klebe S, Henderson DW, et al. Low calretinin expression and high neutrophil-to-lymphocyte ratio are poor prognostic factors in patients with malignant mesothelioma undergoing extrapleural pneumonectomy. J Thorac Oncol. 2011;6(11):19239. PubMed PMID: 22011651. Baseline neutrophil-to-lymphocyte ratio was measured for a cohort of patients with MPM undergoing EPP. High values were associated with poor prognosis.

38. - Creaney J, Francis RJ, Dick IM, et al. Serum soluble mesothelin concentrations in malignant pleural mesothelioma: relationship to tumor volume, clinical stage and changes in tumor burden. Clin Cancer Res. 2011;17(5):1181-9. PubMed PMID: 21177406.
Large prospective study showing high baseline mesothelin levels were indicative of poor prognosis. Also showed that reduction of mesothelin levels with treatment was associated with improved survival.

39. - Grigoriu BD, Chahine B, Vachani A, et al. Kinetics of soluble mesothelin in patients with malignant pleural mesothelioma during treatment. Am J Respir Crit Care Med. 2009;179(10):950-4. PubMed PMID: 19201924. Prospective study of serial mesothelin measurements showing rising levels were associated with a poor outcome.

40. Hollevoet K, Nackaerts K, Gosselin R, et al. Soluble mesothelin, megakaryocyte potentiating factor, and osteopontin as markers of patient response and outcome in mesothelioma. J Thorac Oncol. 2011;6(11):1930-7. PubMed PMID: 21841505.

41. Grigoriu BD, Scherpereel A, Devos P, et al. Utility of osteopontin and serum mesothelin in malignant pleural mesothelioma diagnosis and prognosis assessment. Clin Cancer Res. 2007;13(10):292835. PubMed PMID: 17504993. Epub 2007/05/17. eng.

42. Francis RJ, Byrne MJ, van der Schaaf AA, et al. Early prediction of response to chemotherapy and survival in malignant pleural mesothelioma using a novel semiautomated 3-dimensional volume-based analysis of serial 18F-FDG PET scans. J Nucl Med. 2007;48(9):1449-58. PubMed PMID: 17704250.

43. Nowak AK, Francis RJ, Phillips MJ, et al. A novel prognostic model for malignant mesothelioma incorporating quantitative FDG-PET imaging with clinical parameters. Clin Cancer Res. 2010;16(8):2409-17. PubMed PMID: 20371686.

44. Lee ST, Ghanem M, Herbertson RA, et al. Prognostic value of 18F-FDG PET/CT in patients with malignant pleural mesothelioma. Mol Imaging Biol MIB: Off Publ Acad Mol Imaging. 2009;11(6):473-9. PubMed PMID: 19330385.

45. Lee HY, Hyun SH, Lee KS, et al. Volume-based parameter of 18)F-FDG PET/CT in malignant pleural mesothelioma: prediction of therapeutic response and prognostic implications. Ann Surg Oncol. 2010;17(10):2787-94. PubMed PMID: 20461469. 